\title{
Utilization of Coffee Husk and Pulp Waste as Soil Amendment. A Review
}

\author{
Bikila Takala \\ Ethiopian Institute of Agricultural Research, Jimma Agricultural Research Center, \\ P. O. Box 192, Jimma Ethiopia
}

\begin{abstract}
Coffee is one of the most valuable primary products in the world trade, and also a central and popular part of our culture and the crop is cultivated in about 80 countries across the globe and entangles huge business worldwide. Industrial coffee production involves either a dry or a wet processing method for the removal of the shell and mucilaginous parts from the cherries resulting in the production of coffee husk and pulp, respectively. These main by-products generated by the coffee processing plants and are disposed into arable land and surface water causing environmental pollution due to presence of toxic materials such as caffeine and tannins. To contribute to safe disposal of solid biomass waste in coffee processing many research was conducted to assess the opportunities and challenges of expanded use of solid waste from coffee processing in energy and agricultural services in across coffee producing countries. Therefore the objective of this review was to summarize the literatures and the current knowledge on the utilization of coffee husk and pulp waste for soil amendment, for sustainable agricultural systems within small-scale farming in developing countries like Ethiopia, using these easily available materials as good option for developing plant-nutrient management strategies in highly weathered soil area.
\end{abstract}

Keywords: Coffee husk and pulp, coffee processing, soil amendment, waste management

DOI: $10.7176 / J N S R / 12-11-02$

Publication date:June $30^{\text {th }} 2021$

\section{Introduction}

Coffee is one of the popular beverages of the world and second largest traded commodity after petroleum (Patricia, 2011). Coffee is cultivated in about 80 countries across the globe and entangles huge business worldwide (Murthy and Naidu, 2012). Coffee production is an important sector of the agro-industry in Ethiopia, accounting for about $29 \%$ of the value of all exports in 2018/19(USDA, 2020). Despite its contribution to the national as well as the regional economy, the coffee sector is among the most unsustainable as far as environmental sound solid waste management is concerned. The residue from dry coffee processing is burnt while those from wet processing are dumped into rivers, both being disposed into landfills and surface water (Takele, 2014; Genet and Diriba, 2017). The residue from the wet coffee processing factories particularly coffee processing effluents is causing considerable pollution to the wetlands.

Coffee processing firms generate huge amount of solid wastes (coffee pulp and husk). Because of their abundance, chemical composition and physical characteristics, these residues should be handled in an appropriate way in order to avoid environmental impact as these wastes are easily dumped in to water bodies and unsanitary landfills due to their threat to the environment (Endale, 2016). In spite of the toxic components, coffee husk and pulp are very much rich in organic components and could be used as substrates after bioprocessing to produce enzymes, aroma compounds, edible mushroom plant hormones, organic fertilizer and feeds (Soccol, 2001).

Currently, there are attempts to reduce the volume of these wastes through Integrated Waste Management System (Fikadu et al., 2014; Takele, 2014). This is based on a 3R principles (reduce, reuse and recycle) of all wastes originated from urban, rural and industrial areas of the world (UNEP, 2009). Composting is one of the integrated waste management strategies used for the recycling of organic materials into a useful product because of its eco-compatibility and easy operational procedures (Chane, 1999; Pandey and Soccol, 2000; Endale, 2016).Also the use of organic compost in agriculture is a practice that brings many advantages, avoiding environmental contamination and nutrients immobilization, besides being a source of organic matter in soil.

Therefore the objective of this review was to summarize the literatures and the current knowledge on the utilization of coffee husk and pulp waste for soil amendment, for sustainable agricultural systems within smallscale farming in developing countries like Ethiopia, using these easily available materials as good option for developing plant-nutrient management strategies in highly weathered soil area.

\section{Coffee husk and pulp}

Coffee pulp or husk is a fibrous mucilaginous material (sub-product) obtained during the processing of coffee cherries by wet or dry process, respectively. Coffee pulp/husk contains some amount of caffeine and tannins, which makes it toxic in nature, resulting in the disposal problem. However, it is rich in organic nature, which makes it an ideal substrate for microbial processes for the production of value-added products. Several solutions and alternative uses of the coffee pulp and husk have been attempted as fertilizers, livestock feed, compost, etc. (Pandey 
et al., 2000).

In coffee producing countries, coffee wastes and by-products constitute a source of severe contamination and a serious environmental problem (Gezahegne et al., 2011; Henok and Tenaw, 2014). Since the middle of the last century, efforts have been made to develop methods for its utilization as a raw material for the production of feeds, beverages, vinegar, biogas, caffeine, pectin, pectin enzymes, protein, and compost. The use of fresh or processed coffee pulp has been the subject of numerous studies which, in general, lead to the conclusion that coffee byproducts and wastes can be used in a variety of ways (Rathinavelu and Graziosi, 2005).

Coffee pulp solids contain only one fifth of the nutrients taken out of the soil by export of the green bean. However, it is a good source of humus and organic soil carbon. If coffee pulp is turned over every few days in a heap preserved for a few years as in conventional compost making, it will compost in three weeks into one fifth of the original volume of a stable earthy smelling material which does not attract flies. Left to mature for three months under cover, it will reduce further to become very nice dry earthy compost which is a good soil improver and conditioning agent ( Rathinavelu and Graziosi, 2005; Henok and Tenaw, 2014).

Composition of coffee husk is dependent on cultivation condition, particularly, amount of fertilizers, soil, and kind of coffee (Dzung et al., 2013). Magnesium and Calcium are additional nutrient to N, P and K in coffee husk. However, the better performance of treatments with coffee husk over NPK could be due to the additional presence of $\mathrm{Mg}$ and $\mathrm{Ca}$ in coffee husk. The major mineral elements present in the coffee husk were $\mathrm{N}, \mathrm{P}, \mathrm{K}, \mathrm{Mg}, \mathrm{Ca}$ and $\mathrm{Na}$ (Solomon et al., 2008). Therefore agricultural wastes such as coffee husk are of great efficient importance as degradable organic matter for composting ( Solomon,2006; Nduka et al., 2015).

Despite this, there is always a direct and continuous release of these two important agricultural wastes (coffee husks and flower residues) to the environment. This practice, however, resulted in environmental pollution besides the loss of valuable plant nutrients (Tenaw et al., 2006). According to Murthy and Naidu (2012), coffee wastes such as coffee husk $(\mathrm{CH})$, coffee pulp $(\mathrm{CP})$ and other by-products constitute a source of severe contamination and pose serious environmental problem. As a result, coffee processing units that are located in almost each coffee estate pose threat to the environment because of unsafe disposal of Coffee Husk, Pulp and effluents leading to pollution of water and land around the processing areas (Murthy and Naidu, 2012). Moreover, large-scale utilization and management of $\mathrm{CH}$ around the world still remains a challenge due to its content of caffeine (1\%), free phenols $(\approx 1 \%)$, tannins $(5 \%)$, chlorogenic acids $(2.5 \%)$, which are known to be very toxic to many life processes (Fan et al., 2003). Traditionally, Coffee Husk has found only limited application as fertilizer and livestock feed (Murthy and Naidu, 2012). Nonetheless, it was found suitable for composting since it contains high contents of cellulose and hemicellulose besides potash and lignin. Composting has been demonstrated to be a valuable strategy for recycling of these two wastes, allowing the recovery of denuded land and sustainable management of agricultural/horticultural lands (Tenaw, 2006; Solomon et al., 2008; Genet and Diriba, 2017).

\section{Composting of coffee husk and pulp}

Solid waste composting is a low costing, low technology demanding, less polluting, and more environmentally acceptable method in contrast to the existing system of waste management in the Ethiopia (Solomon, 2006; Genet and Diriba, 2017). Soil organic matter depletion is a critical issue for the health of Ethiopian soils (Melke and Fisseha, 2015). In addition to soil organic matter improvement, many studies on solid waste revealed numerous benefits of composting to the economy and the environment (Fekadu et al., 2014; Endale, 2016).

Composting is one of the biological methods of solid waste treatment and is widely known and accepted as a technology for recycling of agricultural waste materials under aerobic conditions in various corners of the world, the current economic growth, and industrialization necessitate the search for different method to exploit the huge waste biomass (Murthy and Naidu, 2012; Genet, 2016). Composting transforms waste materials into a high quality amendment/fertilizer, rich in organic matter and nutrients. Therefore Composting of coffee by-products could be one mechanism of residue management by utilization. For instance, coffee by-products can be used as soil conditioner, organic fertilizer, mulch, animal feed, alcohol, biogas, caffeine, sugar, pectines, charcoal and heat energy (Soccol, 2001). Currently, there is huge interest from regional and federal government to convert these resources into usable end products such as compost and minimize environmental pollution (Gezahegne et al., 2011).

Coffee husk, a rich organic agricultural waste and potassium was good material for composting process ( Solomon, 2006; Dzung et al. 2013; Henok and Tenaw, 2014). As coffee husks have a high C/N ratio, amendment with cow dung and fruit/vegetable wastes which are rich in easily biodegradable nitrogen compounds, was recommended in order to reduce the $\mathrm{C} / \mathrm{N}$ ratio and to increase the rate of degradation (Fikadu et al.,2014). Thus, co-composting of coffee husk with either cow dung or fruit/vegetable wastes can accelerate the composting process. The use of manure and fruit/vegetable wastes as co-composting materials of coffee husks was shown to result in higher losses in carbon ( Solomon et al., 2008). According to Solomon (2006), high quality compost can be prepared from a mixture of $70 \%$ coffee pulp/husk, $20 \%$ FYM and 10\% top soil or $70 \%$ coffee pulp, $10 \% \mathrm{FYM}, 10 \%$ leguminous plant materials and $10 \%$ top soil(Table 1$)$. 
Also Endale (2016) reported that Composting of coffee processing waste with cow dung, top soil and Khat $(60 \%$ coffee husk $+12 \%$ coffee pulp $+16 \%$ cow dung $+9 \%$ khat and $3 \%$ top soil) for 80 days is important for maturity and to have the necessary plant macronutrients (Table 2). Analytical results of key Physico-chemical properties of raw feedstock, processing compost after 45 days and matured compost after 80 days of composting are tabulated below in table 2 .

Table 1: Quality parameters of coffee pulp compost in piles with different organic residues at the end of composting period (49 days) (Solomon, 2006)

\begin{tabular}{llllll}
\hline Treatments & Moisture (\%) & pH & TN (\%) & OC (\%) & C:N ratio \\
\hline $\mathbf{1}$ & 38.23 & 7.69 & 0.80 & 7.15 & 8.50 \\
$\mathbf{2}$ & 30.89 & 7.49 & 0.81 & 6.71 & 8.30 \\
$\mathbf{3}$ & 36.97 & 7.50 & 0.90 & 6.71 & 7.50 \\
$\mathbf{4}$ & 28.48 & 7.54 & 1.04 & 5.67 & 5.50 \\
$\mathbf{5}$ & 36.12 & 7.60 & 1.06 & 5.62 & 5.30 \\
$\mathbf{6}$ & 34.59 & 7.51 & 0.83 & 5.88 & 7.10 \\
\hline
\end{tabular}

Key: $1=90 \%$ Coffee pulp/husk $+10 \%$ Top soil; $2=80 \%$ Coffee pulp/husk +10 Farm yard manure $+10 \%$ Top soil; $3=70 \%$ Coffee pulp/husk +20 Farm yard manure $+10 \%$ Top soil; $4=80 \%$ Coffee pulp/husk +10 leguminous materials $+10 \%$ Top soil; $5=70 \%$ Coffee pulp/husk +20 leguminous materials $+10 \%$ Top soil; $6=70 \%$ Coffee pulp/husk +10 Farm yard manure +10 leguminous materials $+10 \%$ Top soil.

Table 2. Mean Physico-chemical values of the raw feed stocks, processing and matured compost on days 45 and 80 (Endale, 2016)

\begin{tabular}{|c|c|c|c|c|c|c|c|c|c|c|}
\hline \multirow[t]{2}{*}{ Treatments } & \multicolumn{6}{|c|}{ Parameters } & \multirow[b]{2}{*}{$\mathrm{TN} \%$} & \multirow[b]{2}{*}{$\begin{array}{l}\text { TP } \\
(\%)\end{array}$} & \multirow[b]{2}{*}{$\begin{array}{l}\text { TK } \\
(\%)\end{array}$} & \multirow[b]{2}{*}{$\begin{array}{l}\mathrm{C}: \mathrm{N} \\
\text { ratio }\end{array}$} \\
\hline & $\mathrm{MC} \%$ & DM\% & $\mathrm{pH}$ & $\mathrm{EC}(\mathrm{dS} / \mathrm{m})$ & OM $\%$ & $\mathrm{OC} \%$ & & & & \\
\hline \multicolumn{11}{|c|}{ Raw feedstock } \\
\hline $\mathrm{CH}$ & 11.86 & 88.14 & 5.6 & 1.96 & 87.9 & 50.98 & 1.25 & - & - & 40.8:1 \\
\hline $\mathrm{CP}$ & 82.11 & 17.89 & 8.7 & 4.2 & 70.5 & 40.89 & 2.38 & - & - & $17.2: 1$ \\
\hline $\mathrm{CD}$ & 64 & 36 & 8.1 & 4.2 & 40.3 & 27.37 & 1.69 & - & - & $16.2: 1$ \\
\hline Khat & 60 & 40 & 8.1 & 3.6 & 45.9 & 26.63 & 2.27 & - & - & $11.7: 1$ \\
\hline $\mathrm{TS}$ & 7.9 & 92.1 & 7.9 & 0.14 & 12.5 & 7.25 & 0.25 & - & - & 29.1 \\
\hline \multicolumn{11}{|c|}{ Processing compost after 45 days } \\
\hline $\mathrm{T} 1$ & 68.2 & 31.8 & 8 & 2.4 & 51.5 & 29.87 & 1.09 & 0.09 & 1.3 & 27.4 \\
\hline $\mathrm{T} 2$ & 65.5 & 34.5 & 8.2 & 1.83 & 45.7 & 26.56 & 1.23 & 0.17 & 0.78 & 21.59 \\
\hline T3 & 69.6 & 30.4 & 7.96 & 2.67 & 48.3 & 28 & 1.45 & 0.1 & 0.81 & 19.3 \\
\hline T4 & 64.2 & 35.8 & 7.93 & 2.07 & 47.9 & 27.8 & 1.36 & 0.14 & 0.69 & 20.44 \\
\hline T5 & 67.6 & 32.4 & 8.1 & 1.81 & 45.34 & 26.3 & 1.21 & 0.12 & 0.63 & 21.7 \\
\hline T6 & 68.3 & 31.7 & 7.89 & 2.29 & 46.55 & 27 & 1.22 & 0.13 & 0.74 & 22 \\
\hline \multicolumn{11}{|c|}{ Matured compost after 80 days } \\
\hline T1 & 49.6 & 50.4 & 7.85 & 2.66 & 42.7 & 26.68 & 1.28 & 0.25 & 0.25 & 20.8 \\
\hline $\mathrm{T} 2$ & 39 & 61 & 8.05 & 4.3 & 39.76 & 23.49 & 1.76 & 0.87 & 1.26 & 13.34 \\
\hline $\mathrm{T} 3$ & 40.5 & 59.5 & 8.2 & 3.19 & 39.5 & 22.32 & 1.97 & 1.02 & 0.74 & 11.32 \\
\hline $\mathrm{T} 4$ & 38.4 & 61.6 & 8.1 & 4.4 & 39 & 22.3 & 2.06 & 0.9 & 1.48 & 11 \\
\hline T5 & 40 & 60 & 7.9 & 3.96 & 40.9 & 24.36 & 1.45 & 0.53 & 0.91 & 16.8 \\
\hline T6 & 39 & 61 & 8.0 & 4.15 & 41.6 & 25.3 & 1.71 & 0.49 & 0.85 & 14 \\
\hline
\end{tabular}

Key: $C H=$ coffee husk, $C P=$ coffee pulp, $C D=$ cow dung, $T S=$ top soil, EC=electrical conductivity, $p H=$ power of hydrogen, $O C=$ organic carbon, $O M=$ organic matter, $M C=$ moisture content, $D M=$ dry matter, $T N=$ total nitrogen. $T 1=77 \% \mathrm{CP}+18 \% \mathrm{CH}+5 \% \mathrm{TS}$

$$
\text { T2 }=72 \% \quad C P+15 \%
$$

$\mathrm{CH}+9 \%$

Khat $+4 \% T S, T 3=67 \% C P+14 \% C H+16 \% C D+3 \% T S, T 4=60 \% C P+12 C H+16 \% C D+9 \%$ Khat $+3 \% T S$, $T 5=82 \% C P+13 \% C D+5 \% T S, T 6=72 \% C H+20 \% C D+8 \% T S$.

Coffee processing wastes contain high fraction of organic wastes which can be transformed to valuable agricultural fertilizer through windrow composting which is technically simple, economically viable and easily adaptable to construct anywhere at farmers level within a short period of time(Endale,2016). The compost produced by coffee residue with other organic amendment has high nutrient values which can be used effectively as bio compost (Endale, 2016). The study reported that compost samples composed of coffee residue with Khat waste and cow dung greatly influenced plant growth.

\section{Coffee Husk and pulp Compost as soil amendments}

Decrease in organic matter of the soil is one of the major threats to soils in humid tropical soil and is a critical 
issue for the health of Ethiopian soils (Takele, 2014; Melke and Fisseha, 2015). As a result maintaining or increasing organic carbon is a great challenge in agricultural practices. Application of composts and other organic amendments is an important way of compensation of losses of organic carbon at the same time it is solving the placement and recycling of organic wastes and residues. The culture of utilizing coffee processing by-products for soil fertility improvement is not well established in the country as a whole. However some literatures (Taye et al., 2003; Solomon et al., 2008; Kasongo et al., 2011; Dzung et al., 2013; Kasongo et al., 2013; Nduka et al., 2015;Bikila et al.,2020; Bikila,2020) have indicated that coffee waste is a valuable organic amendment, particularly for highly weathered soils of the humid tropics.

Kasongo et al. (2011) demonstrated the efficiency of coffee waste in improving the physico-chemical quality of Arenosols under humid tropical conditions. Coffee waste application significantly raised the $\mathrm{pH}$ above 5.5 within 3 months and throughout the entire incubation period. It also significantly improved the supply of total N, availability of $\mathrm{P}, \mathrm{Ca}, \mathrm{Mg}$ and $\mathrm{K}$, whereas it immobilized the phytotoxic micronutrient $\mathrm{Mn}$ and mobilized Fe. The $\mathrm{C} / \mathrm{N}$ ratio of the coffee waste amended soils was found within the optimal range (10-14). Soil structural improvement caused by increased organic matter promoted water retention. The relatively high alkalinity and probably the proton consuming ability of humic materials, as well as the high nutrient contents in coffee waste, are considered the main factors responsible for the reduced soil acidity and improved nutrient supply and nutrient retention of the amended soils. This is of particular importance as it indicates the value of coffee waste as an alternative for small-scale farmers who cannot afford to regularly purchase and apply mineral fertilizers (Kasongo et al., 2011).

Also the application of coffee waste greatly stimulated uptake of $\mathrm{Ca}, \mathrm{Mg}, \mathrm{K}, \mathrm{N}$ and $\mathrm{P}$, resulting in a significantly increased dry matter (DM) production over three consecutive cropping cycles of rye grass. Dry matter increased with increasing the coffee waste application rate $(0,5,1020 \mathrm{t} / \mathrm{ha})$ of at least 52,87 and $81 \%$ compared with the un amended controls was obtained for the first, second and third cuts, respectively. Soil analysis after cultivation found that all coffee waste amended soils still contained available macronutrients $(\mathrm{Ca}, \mathrm{Mg}, \mathrm{K}, \mathrm{N})$, which could produce residual effects in subsequent crops. Furthermore, coffee waste application increased soil $\mathrm{pH}$ owing to its liming effect. This brought about an increase in cation exchange capacity with substantial reduction in phytotoxic $\mathrm{Al}$ and a decrease in availability of a number of metals $(\mathrm{Cu}, \mathrm{Zn}, \mathrm{Mn}$ and $\mathrm{Fe})$ and significantly reduced their uptake by ryegrass (Kasongo et al., 2013).

Kasongo et al. (2011), indicated that the marginal and unproductive tropical sandy soils can be improved by the application of coffee waste for the optimization of crop production. The study also suggests that the increased yield (DM) of Italian ryegrass on coffee waste amended soils was the result of improved chemical and physical soil properties by coffee waste application. These benefits of coffee waste application include its capacity to: (i) increase the soil $\mathrm{pH}$, (ii) supply soil nutrients $(\mathrm{N}, \mathrm{K}, \mathrm{P}, \mathrm{Ca}, \mathrm{Mg}$, etc.) and (iii) increase water and nutrient retention (Nduka et al., 2015).

Taye et al. (2003) and Taye (1998) reported that the incorporation of different ratios of organic mixes which contained decomposed coffee husk and farmyard manure significantly affected the status of the soil physicochemical properties with increasing proportion of organic amendments on nursery media at south western Ethiopia.

The organic matter in coffee waste contains more $\mathrm{N}$ and $\mathrm{K}$ than common fertilizers (cow manure, compost, farm residue, chicken manure) ( Solomon, 2006; Kasongo et al., 2011; Henok and Tenaw, 2014). As a result, application of coffee husk compost to tropical sandy soils has shown that it has the potential to be used as a liming material and as 'NPK fertilizer' because of its mineral content compositions such as N, P, K, Mg, Ca and Na. In addition, it can increase water and nutrient retention ( Kasongo et al., 2011; Nduka et al.,2015; Bikila,2020).

Also the study conducted by Takele (2014), showed that the appropriate utilization of bioslurry from coffee husk/pulp as soil amendment not only increases soil fertility but also plays a great role in alleviation of climate change through increment of soil organic carbon which in turn serves as a carbon pool of planet earth.

\section{Effect of Coffee Husk and pulp Compost on Crop Growth}

According to Nduka et al. (2015), coffee husk improved physico-chemical properties of soil, the nutrient in the nursery soil medium and actively supported the morphological development of the cashew seedling. Similar work by Bikila (2020) and Bikila et al. (2020) confirmed that, amending acid soil with coffee husk/ pulp compost improved the soil physicochemical and biological properties that enhanced the coffee seedling growth in western Ethiopia, indicating the potential use of composted coffee husk/ pulp on the field as an alternative source of soil amendment to improve the nutrient content and ameliorate soil acidity problem in Ethiopia. Since good morphological development of seedling enhances their better field establishment, the use of coffee husk to amend nursery soil is recommended. The appropriation of this organic material in agricultural system of nursery seedling production will profitably claim the waste (i.e. coffee husk and pulp) and ultimately supply nutrient to growing seedlings without adverse impact on soil biomes.

Dzung et al. (2013) indicated that cultivation of coffee by using only chemical fertilizers leaded to degradation of the soil and coffee production became unsustainable. Application of compost prepared from coffee husk 
improved the fertility of the soil and $\mathrm{pH}$ of the soil. Particularly, $\mathrm{OC} \%$ and $\mathrm{N} \%$ and total phosphorus enhanced significantly in comparison with the control. Available nutrients and cationic exchange also improved clearly compared with the control. In addition, application of coffee husk compost (CHC) improved physical structure of the soil such as bulk density, particle density and pore space of the soil. Improvement of pore space makes plants adsorption of the nutrients better and effective microorganisms' growth stronger. It is lead to reduce using chemical fertilizer and maintain the fertility of the soil. After three years of the compost application on the coffee field, the study concluded that applying only chemical fertilizers in cultivation of coffee leaded to reducing in $\mathrm{pH}, \mathrm{OC} \%$, total $\mathrm{N} \%, \mathrm{P} \%, \mathrm{~K} \%$ and available nutrients and increasing in degradation of the soil (Dzung et al., 2013).

According to Solomon et al. (2008), compost prepared from coffee processing by-products provided much of the mineral nutrients required by the coffee tree for normal growth and sustained yield. The previous work mentioned above therefore seems to confirm that organic materials such as coffee husk do release $\mathrm{N}, \mathrm{P}, \mathrm{K}, \mathrm{Ca}$ and $\mathrm{Mg}$ into soil when used alone or in combination with NPK. Application of fertilizers as amendments improved the chemical characteristics of the soil. This was in reference to the Integrated Soil Fertility Management (ISFM) principle. The reduction in mineral fertilizer application through their supplementation with organic sources, such as coffee husk makes the use of soil nutrient amendments affordable to small holder farmers, guarantees and improves soil health (Melke and Fisseha,2015; Nduka et al., 2015).

\section{Conclusion and Recommendations}

Coffee is one of the important products, its subsequent processes such as cultivation, processing, trading, transportation, and marketing, provide employment and is a huge business worldwide. With the high crop production projected in the future, there is a vital need to counterpart this production with proper utilization and industrial application of coffee by-products. However culture of utilizing coffee processing by-products for soil amendments and fertility improvement is not well established in the country as a whole. Inorganic fertilizer use is also highly constrained due the prohibitively high price and low level of awareness on plant nutrient management mainly by the smallholder coffee producers. Hence, various activities have been accomplished at Jimma Agricultural Research Center and across the country to assess ways of improving soil fertility through cheap and easily available organic materials in the coffee producing areas of Ethiopia. Much of the work emphasized the utilization of coffee processing by-products, especially coffee pulp and husk. Coffee pulp is usually disposed without any treatment and left to degrade naturally in heaps, with the uncontrolled liberation of noxious odors and nutrient loaded leachate consequently. When it is left for natural degradation, it may take 6 to 8 months to achieve a stabilization of the organic matter. It is therefore believed that composting is a feasible and cheap technology in dealing with byproducts of coffee processing.

Composting of coffee pulp/husk can be done with very low capital investment to produce a very high quality organic fertilizer in a short time than natural stabilization. Applying composts prepared from coffee pulp and husk with different organic residues was found to increase significantly crop yield. Compost prepared from coffee processing by-products can, therefore, provides much of the mineral nutrients required by the crop for normal growth, sustained yield and sustainable soil fertility and health management. Also using compost for soil amendment can be economically feasible and environmentally sound under Ethiopian conditions where soil degradation is severe and low external input for agriculture is common practice due to socio economic situations of the smallholder farmers.

Finally in line with the growing importance of sustainable environmental management thinking, there is need to integrate waste management practices into decision-making at the policy level in coffee factories in Ethiopia. This should take an entrepreneurial approach in order to open opportunities for more income generation to stakeholders besides enhancing environmental health. It is hoped that this review will assist farming communities, factory authorities, researchers, development agents as well as policy makers on maximizing the potential of coffee husk and pulp generated from coffee processing through offering remedial actions in creating jobs and promoting technology transfer beneficial to the area as well as foster environmental management practices.

\section{References}

Bikila, T. 2020. Ameliorative Effects of Coffee Husk Compost and Lime Amendment on Acidic Soil of Haru, Western Ethiopia. Journal of Soil and Water Science. 4(1):141-150

Bikila, T., Taye, K. And Alemayehu. 2020. Effects of lime and coffee husk compost on growth of coffee seedlings on acidic soil of Haru in Western Ethiopia. Journal of Degraded and Mining Land Management. 8(1): 23912400

Chane, A. 1999. Management of coffee processing byproducts for improved and sustainable coffee production in Ethiopia, PhD dissertation, University of Giessen, Germany.

Dzung, N. A., T. T. Dzung and V.T.P. Khanh, 2013. Evaluation of Compost for Improving Soil Fertility and Sustainable Coffee Production in Rural Central Highland of Vietnam. Resources and Environment, 3(4): $77-$ 82 
Endale, W., W. 2016. Composting Of Coffee Husk and Pulp and Co-Digest with Other Organic Wastes. A Thesis Submitted to The School of Graduate Studies of Addis Ababa University In Partial Fulfillment of The Degree of Master of Science In Environmental Engineering. 73pp.

Fekadu, Sh., M.G. Brandon, I. H. Franke, B. Praehauser, H.Insam and F. Assefa, 2014. Coffee husk composting: An Investigation of the Process Using Molecular and Non-Molecular Tools. Waste Management, 34(3): 642652.

Genet, G. 2016. Dynamics of Microorganisms in Compost of Coffee Waste Mixed with Agricultural Wastes, 4(1):001-013

Genet, G., and Diriba, M., 2017. Optimization of Compost Maturity of Coffee Waste Mixed with Agricultural Wastes and Evaluation of Their Effect on Growth of Lettuce (Lactuca Sativa). Journal of Natural Sciences Research. 7(8):82-92

Gezahegne, B., Fikre, L. and Mulatu, W.2011. Exploring the suitability of coffee pulp compost as growth media substitute in greenhouse production. Int J Ag-ric Res., 6(3):255-267

Henok, K. and Tenaw, W.2014.Evaluation of some additives on coffee residue (coffee husk and pulp) quality as compost, southern Ethiopia. International Invention Journal of Agricultural and Soil Science, 2(2):14-21

Kasongo R. K., A. Verdoodt, P. Kanyankagote, G. Baert, and E. Van Ranst. 2011. Coffee Waste as an Alternative Fertilizer with Soil Improving Properties for Sandy Soils in Humid Tropical Environments. Soil Use and Management, 27: 94-102

Kasongo, R. K., A. Verdoodt, P. Kanyankogote, G. Baert, \&E.Van Ranst. 2013. Response of Italian Ryegrass (Lolium Multiflorum Lam.) to Coffee Waste Application on a Humid Tropical Sandy Soil. Soil Use and Management, 29: 22-29

Melke, A. and Fisseha, I. 2015. Nutritional Requirement and Management of Arabica Coffee (Coffea arabica L.) in Ethiopia : National and Global Perspectives. American Journal of Experimental Agriculture, 5 (5): 400 418

Murthy, P.S. and Naidu, M.M. (2012). Sustainable management of coffee by-products and value addition-a review. Resour.Conserv.Recycl. 66:45-58.

Nduka, B.A., D. B. Adewale, O.S.O. Akanbi, and K. B. Adejobi. 2015. Nursery Soil Amendments for Cashew Seedling Production: A Comparative Analysis of Coffee Husk and NPK. Journal of Agricultural Science, 7(3):111-122

Pandey, A. and Soccol C.R. (2000). Economic utilization of crop residues for value addition. A futuristic approach. J.Sci. Ind. Res. 59: 12-22.

Pandey, A., C. R. Soccol, P. Nigam and D. Brand. 2000. Biotechnological Potential of Coffee Pulp and Coffee Husk for Bioprocesses. Biochemical Engineering Journal, 6:153-162

Patricia, F., 2011. The Coffee Exporter's Guide. 3rd eds., International Trade Centre, Geneva. 247pp.

Rathinavelu R., and G. Graziosi. 2005. Potential Alternative Use of Coffee Wastes and by-products. ICS-UNIDO, Science Park, Padriciano, Trieste, Italy; Department of Biology, University of Trieste, Italy.

Soccol, C.R. (2001). New potentialities and uses of coffee agro-industrial wastes for production of bioproducts in Brazil. Biotechnol. 18: 26.

Solomon, E., Tesfu, K. and Tesfaye, Y. 2008. Inorganic fertilizer management and coffee production. 217-225. In: Coffee Diversity and Knowledge (Girma,A.; Bayetta, B.; Tesfaye, Sh.; Endale, T. and Taye,K. ed.).Proceedings of National Workshop Four Decades of Coffee Research and Development in Ethiopia, 1417 August 2007, Addis Ababa (Ghion hotel), Ethiopia.

Solomon, E.2006.Accelerated composting of coffee processing by products: an organic option for soil fertility management in the coffee based cropping system of south western Ethiopia. Proceeding of $21^{\text {st }}$ International scientific conference on coffee science (ASIC), Montpelier, France, pp 1084-1089.

Takele, U.2014.Investigation of Environmental and Economic Benefits of Bioslurry from Coffee Husk Relative to Chemical Fertilizer. A Thesis Submitted to The School of Graduate Studies of Addis Ababa University In Partial Fulfillment of The Degree of Master of Science In Environmental Engineering. 50pp.

Taye, K., Mesfin, A., Paulos, D. 2003. Contribution of organic amendment to physico-chemical conditions of coffee nursery media, 25-40. In: Tilahun A, Eylachew Z (eds). Proceedings of the Sixth Conference of the Ethiopian Society of Soil Science (ESSS) on Challenges of Land Degradation to Agriculture in Ethiopia, Feb 28-March 1, 2002, Addis Ababa, Ethiopia.

Taye, K.1998. Response of Arabica coffee (Coffea arabica L.) to various soil fertility management. Thesis presented to the school of graduate studies Haramaya University of Agriculture. In partial fulfillment of the requirement for the degree master of science in agriculture (agronomy), Haramaya, Ethiopia.137pp

Tenaw, W., Husni, M.H.A., Anuar., A.R. and Zaharah, A.R. (2006). Effect of coffee bean residues and time on soil nitrogen availability. Malay.J.Soil.Sci.10:53-65.

UNEP (2009). Developing integrated solid waste management plan training manual. pp 2. International Environmental Technology Center. Osaka/Shiga, Japan. 
United States Department of Agriculture (USDA), 2020. Coffee annual report: GAIN (Global Agricultural Information Network) USDA foreign Agricultural Service report Number: ET2020-0004. 